\title{
The effect of supply chain and storage management on demand for health services
}

\author{
Nabil Mohemmed Al-Hazmia,b*
}

${ }^{a}$ Associate Professor of Marketing, Department of Marketing, College of Business Administration Prince Sattam bin Abdulaziz University-Kingdom of Saudi Arabia

${ }^{b}$ Associate Professor of Marketing, College of Administrative Sciences, Taiz University, Yemen

\section{H R O N I C L E}

\begin{tabular}{l}
\hline Article history: \\
Received January 2, 2021 \\
Received in revised format \\
January, 25, 2021 \\
Accepted May 92021 \\
Available online \\
May 92021 \\
\hline Keywords: \\
Supply Chain Management \\
Storage \\
Demand \\
Health Service \\
Hospitals
\end{tabular}

\section{A B S T R A C T}

\begin{abstract}
This study aims at studying the effectiveness of supply and storage management in light of the determinants of demand for health services in Saudi hospitals in an analytical framework. The survey studies the impact of logistical management of medical materials and its vital role in securing the necessary medical resources and supplies for the health institution. The study adopts the descriptive and analytical approach in order to achieve its goals and test its hypotheses, as the study was applied in the hospitals of Al-Kharj Governorate. The study finds that there was a relationship between the methods of supply and storage applied in Saudi hospitals and the determinants of demand for the health services provided. The study recommends working on developing methods of requesting suppliers, developing methods of storing medicines and medical supplies, and distributing them inside the hospital in accordance with economic standards and making use of computer technologies.
\end{abstract}

\section{Introduction}

Supply chain management is defined as the processes of organizational and strategic coordination of regular business functions and the planning of these functions within the company and through a business group within the supply chain in order to improve the long-term performance of individual companies and the supply chain as a whole. The unprecedented development in various fields, environmental transformations, economic depression and sufficiency requires institutions of whatever sector (public or private) to reform their administrative policies to control expenses. As these developments and transformations led to the incitement of thinking, to reuse the various available resources and means, such as human resources and equipment used for transportation and storage, reduce waste and supply costs in the most effective ways in all institutions in general and in health institutions in particular. From here, applied studies that study the problem of supply and storage based on the determinants of health demand have taken a distinguished place in administrative studies in developed countries. The first applied studies in this field were limited to measure the average consumption and the factors responsible for it in the long term, and discussion continued on applied studies to estimate the volume of demand for medicines and testing the appropriate variables in different models until today, due to several factors such as the different conditions of the hospitals under study in terms of volume, type and location of the hospital. The difference in the time scope of the study and its objective, has given the health sector a special and distinctive importance, which makes it a vital field in which there are multiple researches to reach scientific facts that serve the decision-maker to achieve a vision and future planning for public policies for hospitals in general. It is evident that the effective use of resources and the search for a high-quality service for patients leads to stimulating thinking in the field of supply and supply management and pushes officials to find a difficult balance and to discover new paths to rationalize expenses and search for accurate solutions to the problems and difficulties of improving the management of flows and stocks. Therefore, this study seeks to identify the

* Corresponding author

E-mail address: alhazmi1976@gmail.com (N. M. Al-Hazmi)

(C) 2021 by the authors; licensee Growing Science.

doi: $10.5267 /$ j.uscm.2021.5.002 
problem of supply and storage in the health sector in the Kingdom of Saudi Arabia in light of the determinants of demand for health services and to identify the most important factors affecting them.

\subsection{Study problem}

The problem of this study seeks to answer the following questions:

1. What is the relationship between the volume of supply and storage and the determinants of the demand for health service?

2. How can the volume of the necessary supply and the appropriate storage volume of medical materials and equipment be determined for the hospital?

\subsection{Study importance}

The importance of this study is that it is the first study to be conducted in health organizations and seeks to provide solutions and proposals that increase the effectiveness of supply chains and warehousing operations and reduce waste of resources in light of the determinants of demand for health services in the governorate.

\subsection{Study objectives}

The study aims at:

1- Applying scientific methods in supply management based on the determinants of health service demand, and clarifying the dimensions of the supply problem and storage difficulties.

2- Clarifying the relationship between the volume of supply, the volume of storage and the determinants of the demand for the health service.

\subsection{Research hypothesis}

1- There is no significant relationship between the volume of demand for medical materials and the determinants of the demand for health services.

2- There is no statistically significant relationship between the applied supply and storage methods and the determinants of the demand for health services.

3- There are no differences between the determinants of demand for health services and the type, volume and location of the hospital.

\subsection{Study methodology}

In order to achieve the study objectives, the descriptive and analytical approach was used. Secondary data were collected from various sources, represented by books, scientific journals, statistics and previous studies. A questionnaire form was prepared and distributed to the study sample in order to collect primary data and different specialized methods were used in its analysis.

\subsection{Study population \& Sample}

The study population consists of all hospitals that provide health services in Al-Kharj governorate, public and private. All these hospitals were selected as a sample for the study, as their number reached 12 hospitals and medical dispensaries in Al-Kharj city and its suburbs.

\section{Literature Review}

There are few studies that dealt with the subject of the study, the most important of which are:

Hassan (2019) aimed at studying the mechanisms of supply and storage under the determinants of the student on health services. The study recommended the adoption of clear policies and mechanisms in the process of supplying and storing in the hospitals under study, and working on the introduction of electronic means in the storage and supply process. Another study recommended the necessity of preparing and designing a clear strategy for organizations when carrying out supply and storage operations for the requirements of the production process through the introduction of electronic systems and sophisticated warehouse operations. Abu Zaid (2014) aimed to examine the direct impact of competitive precedence on institutional performance, and the indirect impact through the supply chain strategy. Hawa (2018) recommended the necessity of activating electronic means in the supply and storage operations because of their role in achieving total quality and thus gaining customer satisfaction and loyalty to the organization. The study of Al-Ajili (2018) aimed at identifying the 
role of supply strategies in the process of marketing integration and achieving the marketing objectives of food organizations. Hosain (2019) recommended the need to work on developing supply and storage strategies in order to increase the production efficiency of organizations and work to adhere to the principles of total quality in supply and storage operations. The study by Jassim (2019) aimed at identifying researchers' views on defining the concept of supply chain, as well as diagnosing the nature of the relationship between supply chain strategies and competitive advantage. Abdulsllam (2018) aimed to determine the role of supply and storage strategies in the competitive advantage of productive organizations. It recommended working on training workers on methods of preparing modern supply and storage strategies. Another study Ali et al. (2020) recommended that the green supply chain department should design and produce green products that can be reused and recycled to reduce the excessive use of resources and reduce the amount of waste. Al-Hazmi (2020) recommended the necessity of working on the introduction of electronic means in the procurement, supply and storage processes for travel and tourism organizations in the Al-Kharj Governorate. Al-Hazmi (2021) recommended the necessity of limiting and addressing the obstacles to electronic distribution of tourism services in the Saudi city of Al-Kharj by training workers to use modern systems in the operations, storage and distribution of services of these organizations.

From the foregoing studies, we find that most of them were conducted in regions other than the Al-Kharj Governorate and dealt with other topics than the subject of the study. Hence, this study breaks down from previous studies that it dealt with the operations of supply and storage of health services in the city of Al-Kharj, Saudi Arabia, and thus it is considered the first study, which dealt with this topic in the area.

\section{The applied study}

First: To study the relationship of supply and storage management with the determinants of demand

Based on the field study data, we will try to approach reality in our analytical study of the relationship of supply and storage management with the determinants of demand for health services in hospitals in Al-Kharj city. Fig. 1 shows distribution of the hospitals in terms of type, location and size.

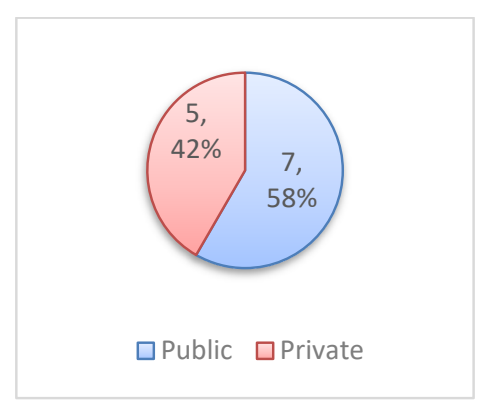

Type

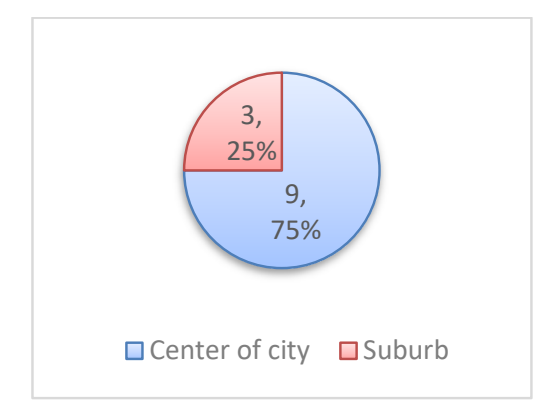

Location

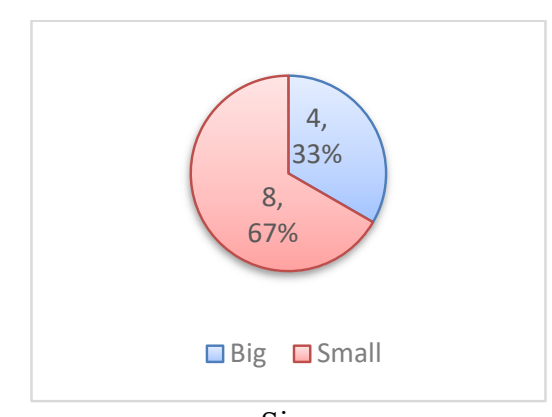

Size

Fig. 1. Characteristics of the hospitals

According to Fig. 1, we find that public hospitals are 58\% and private hospitals $42 \%$, while the percentage of hospitals in the city center is $75 \%$ and in the suburbs $25 \%$, and the percentage of large hospitals is $33 \%$ compared to small hospitals that represent $67 \%$. (Small hospital from 10 to $50 \mathrm{Bed}$, the big hospital over 50 beds).

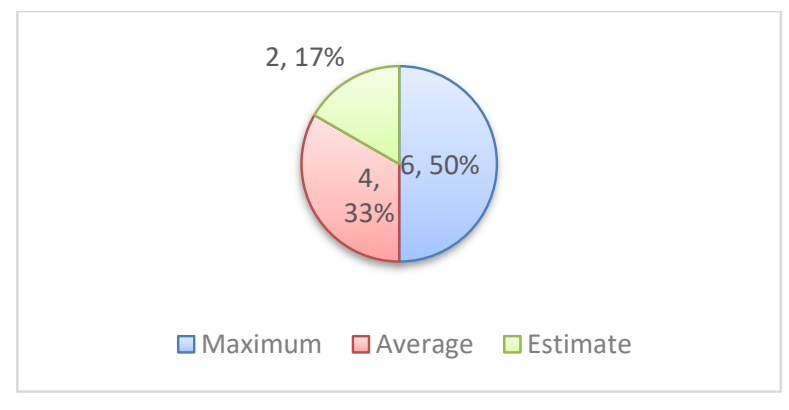

Determinants of medicines demand at the hospital level

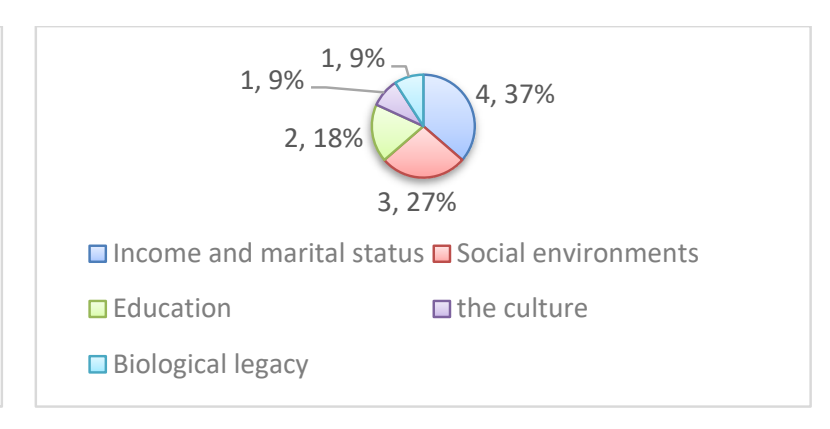

Type of demand

Fig. 2. Determinants of medicines demand at the hospital level

According to Fig. 2, percentages indicate that $50 \%$ of hospitals adopt the maximum number of patients to accommodate when ordering medicines, according to their supply officials. We also find that the most important determinants of demand for health services are income and marital status $33.0 \%$, followed by the social environment $25.0 \%$, and the cultural aspect and biological heritage $1 \%$. 
Second: Testing the hypotheses of the study

1- Results of the first hypothesis test: The relationship between the volume of demand for medical materials and the determinants of the demand for health services

The study uses regression analysis to examine the first hypothesis of the survey. Table 1 demonstrates the summary of the regression analysis.

Table 1

The summary of the regression analysis for testing the first hypothesis of the survey

\begin{tabular}{|c|c|c|c|c|c|c|}
\hline & & \multicolumn{2}{|c|}{$\begin{array}{l}\text { Unstandardized } \\
\text { Coefficients }\end{array}$} & \multirow{2}{*}{$\begin{array}{c}\begin{array}{c}\text { Standardized } \\
\text { coefficients }\end{array} \\
\text { Beta }\end{array}$} & \multirow[t]{2}{*}{$\mathrm{t}$} & \multirow[t]{2}{*}{ Sig. } \\
\hline & Model & $\mathrm{B}$ & Std. Error & & & \\
\hline & (Constant) & 1.768 & 0.495 & & 3.623 & $\cdot, \ldots r$ \\
\hline 1 & Determinants of demand for health services & 0.724 & 0.064 & 0.152 & 4.647 & 0.005 \\
\hline
\end{tabular}

a Dependent Variable: Determinants of drug request

b Independent Variable: (Constant), Determinants of demand for health services

Spearman's rho $=0.799(0.005)$ R-Square $=0.763$ Adjusted R-Square $=0.742$ Standard Error of the estimate $=1.128 \mathrm{~F}$-value $=0.496(0.005)$

It is clear from the results of Table 1 that the value of the Spearman correlation coefficient is equal to 0.799 and the value of the calculated level of significance is equal to $\cdot<\cdot / \bullet$, this leads us to confirm that there is a positive relationship between the methods of supply and storage applied and the determinants of demand for health services, which is a very strong relationship. The results also indicate that the value of the correlation coefficient between the volume of demand for medical materials and the determinants of demand for health services is 0.8219 , which indicates the existence of a strong direct correlation between them. It is clear from the above table that the value of the coefficient of determination $\mathbf{R}^{2}=0.763$, which is high, and this indicates that the regression equation or prediction is good. We also find that a value of $\mathrm{F}=0.496$, which indicates that there is a significant relationship between the demand for medical materials and the determinants of the demand for health services and that the previous regression model is good, and this means accepting the regression equation. Finally, t-value for both constant and independent variables are meaningful when the level of significance is one percent. Therefore, the first hypothesis is confirmed.

2. Results of testing the second hypothesis: The relationship between the methods of supply and storage applied and the determinants of the demand for health services

The study uses regression analysis to examine the first hypothesis of the survey. Table 2 shows the summary of the regression analysis.

Table 2

The summary of the regression analysis for testing the second hypothesis of the survey

\begin{tabular}{|c|c|c|c|c|c|c|}
\hline \multirow{2}{*}{\multicolumn{2}{|c|}{ Model }} & \multicolumn{2}{|c|}{$\begin{array}{l}\text { Unstandardized } \\
\text { Coefficients }\end{array}$} & \multirow{2}{*}{$\begin{array}{c}\begin{array}{c}\text { Standardized } \\
\text { coefficients }\end{array} \\
\text { Beta }\end{array}$} & \multirow[t]{2}{*}{$\mathrm{t}$} & \multirow[t]{2}{*}{ Sig. } \\
\hline & & $\mathrm{B}$ & Std. Error & & & \\
\hline & (Constant) & 1.768 & 0.495 & & 3.623 & $\cdot, \cdot r$ \\
\hline 1 & Determinants of demand for health services & 0.724 & 0.064 & 0.152 & 4.647 & 0.005 \\
\hline
\end{tabular}

a Independent Variable: Constant, Determinants of demand for health services

b Dependent Variable: Determinants of drug request

Spearman's rho $=0.801(0.007)$ R-Square $=0.504$ Adjusted R-Square $=0.500$ Standard Error of the estimate $=1.359 \mathrm{~F}-\mathrm{value}=1.003(0.015)$

According to Table 2, we find that the value of the Spearman correlation coefficient is equal to 0.722 , and the value of the calculated level of significance is equal to $\mathrm{P}-\mathrm{Value}=\mathrm{Sig}=0.05<0.007$. The alternative hypothesis is that there is a relationship between the applied supply and storage methods and the determinants of the demand for health services, which is a strong relationship as indicated by the value of the correlation coefficient. We also note that the value of the correlation coefficient between the applied supply and storage methods and the determinants of the demand for health services $\mathrm{R}=$ 0.504, which indicates the existence of a strong direct correlation between them. As follows: $51 \%$ of the change in the applied supply and storage methods (the dependent variable) can be explained using the linear relationship between the applied supply and storage methods and the determinants of the demand for health services, and the remaining $47 \%$ is due to other factors that affect the applied supply and storage methods. From the above table, $\mathrm{F}=1.359(0.012)$. This indicates that there is a significant relationship between the applied supply and storage methods and the determinants of the demand for health services and that the previous regression model is good. Finally, t-value for both constant and independent variables are meaningful when the level of significance is one percent. Therefore, the second hypothesis is confirmed.

\section{Results of the third hypothesis test: The relationship between the determinants of the demand for health services and the hospital type, volume and location}

We first present the results of Levens's test of equality on error of variances. 
Table 3

The results of Levene's test of equality on error of variances

\begin{tabular}{cccc} 
F & df1 & df2 & Sig. \\
3.989 & 9 & $\wedge$ &.$/ 9 \Delta r$ \\
\hline
\end{tabular}

The results of Table 3 indicate that the Levene's statistic value is equal to $F=3.989$, and the value of $\operatorname{Sig}=0.653>\cdot / \cdot \Delta$. This leads us to accept the unacceptable hypothesis of the homogeneity of the variance between samples. Table 4 presents the results of Analyse of Variance.

Table 4

The results of ANOVA test (Dependent variable: Determinants of demand for health services)

\begin{tabular}{lccccc}
\hline \multicolumn{1}{c}{ Source } & Type III Sum of Squares & df & Mean Square & F & Sig. \\
\hline Corrected Model & $129.324(\mathrm{a})$ & $\wedge$ & 14.257 & 1.504 & 0.195 \\
Intercept & 449 & 1 & 456.121 & 52.102 & 0.000 \\
Type of Hospital & 7.951 & $r$ & 4.129 & 0.458 & 0.022 \\
Hospital Location & $4 / 4 \Delta 9$ & $r$ & $r / r r$ & 0.359 & 0.004 \\
Size of Hospital & $4 / 0 \wedge \mathrm{V}$ & 2 & 3.251 & 0.368 & 0.005 \\
Error & 106.000 & 11 & 8.852 & & \\
\hline Total & 1012.000 & 21 & & & \\
Corrected Total & 239.431 & 20 & & & \\
\hline
\end{tabular}

a R Squared $=.553$ (Adjusted R Squared $=0.218$ )

Based on Table 4, we reject the null hypothesis that there are no differences between the average determinants of health demand according to the hospital type variable. Because the value of the test significance level for the variable Pvalue $=\mathrm{Sig}=0.022$ is less than the level of the unacceptable hypothesis $\alpha=0.05$. Therefore, there are differences in the averages of the determinants of health demand according to the hospital type variable. We reject the unacceptable hypothesis that there are no differences between the averages of the determinants of health demand according to the hospital location variable because the test significance level value of $\mathrm{Sig}=0.004$ is less than the significance level of the null hypothesis $\mathrm{a}=0.05$. Then there are differences in the averages of the determinants of health demand according to the hospital location variable. We also reject the unacceptable hypothesis that there are no differences between the mean determinants of health demand according to the hospital size variable because the test significance level value Sig $=0.005$ is less than the null hypothesis significance level $\alpha=0.05$ Then there are differences in the averages of the determinants of health demand according to the hospital size variable. Now, we present the results of multiple comparison between different components. Table 5 presents the results of pair-comparison between the determinants of demand for health services and the type of hospital.

Table 5

Pair- comparisons between the determinants of demand for health services and the type of hospital

\begin{tabular}{|c|c|c|c|c|c|c|c|}
\hline & \multirow[b]{2}{*}{$\begin{array}{l}\text { (I) Type of } \\
\text { Hospital }\end{array}$} & \multirow[b]{2}{*}{$\begin{array}{l}\text { (J) Type of } \\
\text { Hospital }\end{array}$} & \multirow{2}{*}{$\begin{array}{c}\text { Mean } \\
\text { difference } \\
(\mathrm{I}-\mathrm{J})\end{array}$} & \multirow[t]{2}{*}{$\begin{array}{l}\text { Std. } \\
\text { Error }\end{array}$} & \multirow[t]{2}{*}{ Sig. } & \multicolumn{2}{|c|}{$\begin{array}{l}\text { 95\% Confidence } \\
\text { Interval }\end{array}$} \\
\hline \multirow{3}{*}{ Bonferroni } & & & & & & $\begin{array}{l}\text { Lower } \\
\text { Bound }\end{array}$ & $\begin{array}{l}\text { Upper } \\
\text { Bound }\end{array}$ \\
\hline & Public & private &.$/ F T$ & $r / f \Delta q$ & •/. MI & -4.868 & 5.102 \\
\hline & private & Public & IXFT & ITR & $1 / \ldots$ & -4.157 & $\Delta / \wedge 9 \Delta$ \\
\hline
\end{tabular}

Dependent Variable: Determinants of demand for health services

According to Table 5, we find that, there is a significant difference between the determinants of the demand for health services according to the type of hospital, civil public hospitals and private hospitals, because the value of the calculated level of significance is smaller than the level of significance $\mathrm{P}$-value $=\mathrm{Sig} .=0.031$, as shown by the sixth column entitled B. Sig, which is for public hospitals. Similarly, Table 6 presents the results of pair comparison between the location of the hospitals. According to Table 6, we find that there are differences between large hospitals and small hospitals, because the value of the calculated level of significance is smaller than the level of significance $\mathrm{P}$-value $=\mathrm{Sig}$. $=0.021<0.05$. It is in favor of the hospitals in the city center.

Table 6

Pair- comparisons between the determinants of demand for health services and the type of hospital

\begin{tabular}{|c|c|c|c|c|c|c|c|}
\hline & \multirow[b]{2}{*}{ (I) Type of Hospital } & \multirow[b]{2}{*}{ (J) Type of Hospital } & \multirow{2}{*}{$\begin{array}{c}\text { Mean } \\
\text { difference } \\
(\mathrm{I}-\mathrm{J})\end{array}$} & \multirow[t]{2}{*}{$\begin{array}{l}\text { Std. } \\
\text { Error }\end{array}$} & \multirow[t]{2}{*}{ Sig. } & \multicolumn{2}{|c|}{$\begin{array}{l}95 \% \text { Confidence } \\
\text { Interval }\end{array}$} \\
\hline \multirow{3}{*}{ Bonferroni } & & & & & & $\begin{array}{l}\text { Lower } \\
\text { Bound }\end{array}$ & $\begin{array}{l}\text { Upper } \\
\text { Bound }\end{array}$ \\
\hline & City Center & Suburb Of The City & 1.301 & 1.698 & 0.594 & -5.589 & 3.649 \\
\hline & Suburb Of The City & City Center & 0.397 & 2.093 & 0.025 & -4.837 & 6.397 \\
\hline
\end{tabular}

Dependent Variable: Determinants of demand for health services 
Finally, we present the summary of the pair-compasison between three groups of hospitals in Table 7 .

Table 7

The summary of the pair-comparison between three groups of hospitals

\begin{tabular}{|c|c|c|c|c|c|c|c|}
\hline & \multirow[b]{2}{*}{$\begin{array}{l}\text { (I) Size Of The } \\
\text { Hospital }\end{array}$} & \multirow[b]{2}{*}{ (J) Size Of The Hospital } & \multirow{2}{*}{$\begin{array}{c}\text { Mean } \\
\text { difference } \\
\text { (I-J) }\end{array}$} & \multirow[t]{2}{*}{$\begin{array}{l}\text { Std. } \\
\text { Error }\end{array}$} & \multirow[t]{2}{*}{ Sig. } & \multicolumn{2}{|c|}{$\begin{array}{c}95 \% \text { Confidence } \\
\text { Interval }\end{array}$} \\
\hline \multirow{7}{*}{ Bonferroni } & & & & & & $\begin{array}{l}\text { Lower } \\
\text { Bound }\end{array}$ & $\begin{array}{l}\text { Upper } \\
\text { Bound }\end{array}$ \\
\hline & \multirow[t]{2}{*}{ Big Hospital } & Medium Hospital & 1.092 & 1.734 & 1.000 & -6.251 & 4.005 \\
\hline & & Small Hospital & 0.154 & 1.310 & 0.014 & -3.348 & 4.046 \\
\hline & \multirow[t]{2}{*}{ Medium Hospital } & Big Hospital & 1.047 & 1.763 & 1.000 & -4.000 & 5.634 \\
\hline & & Small Hospital & 0.522 & 1.938 & 0.001 & -4.092 & 6.583 \\
\hline & \multirow[t]{2}{*}{ Small Hospital } & Big Hospital & 0.214 & 1.807 & 0.984 & -4.197 & r/^^৭ \\
\hline & & Medium Hospital & 0.549 & 1.786 & 0.031 & -6.895 & $\varphi, Y)$. \\
\hline
\end{tabular}

Dependent Variable: Determinants of demand for health services

From Table 7, we find that there are differences between large hospitals and small hospitals, because the value of the calculated level of significance is smaller than the level of significance

\section{Conclusion}

Through the analysis of the study data, we have found that, most hospitals adopt the maximum number to accommodate patients, and the majority of hospitals have shown a lack of knowledge and application of scientific methods of supply chain management for storage as they depend entirely on their memories, which caused the emergence of cases of depletion and damage to major medical materials or a shortage of these materials and may lead to order in quantities that exceed the need and good storage capacity. Hospital administrators see the possibility of controlling the reduction of spending and waste on medical services by following scientific methods in managing demand and correct storage of medical consumables by taking advantage of knowledge of the relationship between the volume of demand and the determinants of demand for health services. The results have indicated that there is a relationship between the applied supply and storage methods and the determinants of the demand for health services. Accordingly, the medical staff must be trained to adopt protocols for the most consuming medical materials associated with the most common diseases or high cost, based on the determinants of the demand for health services, and review the costs of spending and ensure that it is distributed according to the priorities and need of the service. The methods of requesting suppliers must be developed, methods of storing medicines and medical supplies, and distributing them within the hospital in accordance with economic standards, making use of computer technologies, and the need to use analytical tools that help formulate health policies to provide data, information, training and studies that help them apply modern scientific methods in supply chain management and storage.

\section{References}

Abdulsllam, T. (2018). The role of supply chain management activities in enhancing competitive advantage. Journal of Economic Sciences, $r(\wedge)$, r r r frr.

Abu zaid, S. $\left(201^{\uparrow}\right)$. The causal relationship between competitive precedents, supply chain strategy, and their impact on organizational performance. The Jordanian Journal of Business, $4(1 \cdot), 944-944$.

Al-Hazmi, N. (2020). The impact of information technology on the design of distribution channels.Uncertain Supply Chain Management, 8(3), 505-512.

Al-Hazmi, N. (2021). Determinants of the electronic distribution of services to tourism organizations in the Kingdom of Saudi Arabia. Management Science Letters, 11(3), 807-812.

Al-Ajili, A. (2018). The Impact of Supply Chain Practices integration on Marketing Performance at Food Industrial Firms in Gaza Strip. Journal of Business and Finance, 5(7), 683-701.

Ali, Y., Saad, T. B., Sabir, M., Muhammad, N., Salman, A., \& Zeb, K. (2020). Integration of green supply chain management practices in construction supply chain of CPEC. Management of Environmental Quality: An International Journal, 31(1), 185-200.

Hawa, J. (2018). The Impact of Logistics Management on Customer Satisfaction. Entrepreneurship and Business Magazine, (r), rNI-rar.

Hassan, T. (2019). Managing supply and storage based on the determinants of demand for health services. Damascus University Journal of Economic and Legal Sciences, 4(30), 431-445.

Hosain, A. (2019). The Strategies of supply chain and its impact to achieve the competitive advantage. Scientific Journal of Economics and Trade, $4(9)$, V।A vry.

Jassim, M. (2019). The Impact of Supply Chain Practices integration on Marketing Performance at Food Industrial Firms in Gaza Strip. Journal Al-Qadisiyah Journal of Administrative and Economic Sciences, 12(2), 458-469.

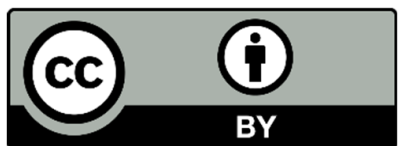

(C) 2021 by the authors; licensee Growing Science, Canada. This is an open access article distributed under the terms and conditions of the Creative Commons Attribution (CC-BY) license (http://creativecommons.org/licenses/by/4.0/). 